Association for Information Systems

AIS Electronic Library (AISeL)

\title{
Promoting Carpooling through Nudges: The Case of the University Hildesheim
}

Coralie Werkmeister

Universität Hildesheim

Thorsten Schoormann

Universität Hildesheim

Ralf Knackstedt

Universität Hildesheim

Werkmeister, Coralie; Schoormann, Thorsten; and Knackstedt, Ralf, "Promoting Carpooling through Nudges: The Case of the University Hildesheim" (2021). Wirtschaftsinformatik 2021 Proceedings. 12. https://aisel.aisnet.org/wi2021/XStudent/Track03/12

This material is brought to you by the Wirtschaftsinformatik at AIS Electronic Library (AISeL). It has been accepted for inclusion in Wirtschaftsinformatik 2021 Proceedings by an authorized administrator of AIS Electronic Library (AISeL). For more information, please contact elibrary@aisnet.org. 


\title{
Promoting Carpooling through Nudges: The Case of the University Hildesheim
}

\author{
Coralie Werkmeister ${ }^{1}$, Thorsten Schoormann ${ }^{1}$, and Ralf Knackstedt ${ }^{1}$ \\ ${ }^{1}$ Institute for Business Administration and Information Systems, \\ Department of Information Systems and Enterprise Modeling (ISUM), Hildesheim, Germany \\ cora.werkmeister@googlemail.com; \{thorsten.schoormann, ralf.knackstedt\}@uni-hildesheim.de
}

\begin{abstract}
Mobility is an essential need that requires novel opportunities enabling us to travel more sustainably. In attempting to address this, our university-the University Hildesheim—, located within a city of about 100.000 residents seeks to improve especially the student's and employee's arrival approaches to, for instance, reduce greenhouse emissions caused by traffic, relax the current parking situation, and limit traffic jams. By drawing on a literature review, an analysis of a university-wide mobility survey, and several interviews, this study (1) deduced a set of eight requirements for choosing more environmentally-friendly mobility options and (2) developed a mobile application (app) that promotes carpooling through the help of digital nudges. With this, we hope to contribute to current mobility challenges especially due to increased traffic.
\end{abstract}

Keywords: Sustainability, Green mobility, Digital nudging, Design science.

\section{Introduction}

Mobility is one of the fundamental needs of our modern world. Through mobility, there is a wide range of possibilities for our society and for companies such as worldwide traveling to meet our family and friends, to arrive at our workplace, as well as to experience other cultures and countries. Due to challenges such as in terms of climate change, it is however a necessary prerequisite to create mobility solutions that are affordable for everyone without accelerating the deterioration of the natural environment. Particularly the pollution caused by car traffic plays a big role in the overall greenhouse emission, which is evident by several facts: In Europe, transportation is the most significant source of $\mathrm{CO}_{2}$ [1]; in Germany, transportation makes 165 tons of $\mathrm{CO}_{2}$, representing 20,5\% of the overall greenhouse emission [2]; car traffic takes $60,6 \%$ of that-so, overall $12,4 \%$ of the emission in Germany [3].

In addition to these general facts, it is also a great challenge in local areas. In line with this, at our university - the University Hildesheim, Germany-mobility is one of the most important problems because there are, for example, only very restricted areas for parking lots causing complaints from residents as well as employees who have to handle long times for searching free spaces, high emission values, and an increased volume of traffic causing in traffic jams. Nonetheless, as shown by a recent survey on 
mobility conducted by the Green Office Hildesheim [4], the most preferable option to arrive at our university is still by car. In consequence, there is a need for employing novel approaches such as carsharing [5,6], carpooling, or self-driving services [7] that help to reduce car traffic and thereby lower negative impacts on the environment.

A promising approach to open up the possible solution space of mobility options as well as to foster the selection of options that are more sustainable (e.g., in terms of emissions caused by driving cars individually) is given by nudging. In broad terms, nudging can be used as a tool to increase the transparency of decision situations so that people, hopefully, choose more sustainable mobility options more frequently without intervening in the people's opinion [8]. According to Thaler and Sunstein [9], a nudge "is any factor that significantly alters the behavior of humans" (p. 6). Since information systems (IS) are generally seen as an enable for new mobility services and business models in the context of sustainability $[10,11]$, this study focuses on 'digital nudging'. When nudging digitally, (technology-driven) user-interface design elements are involved to intervene in choices $[12,13]$. Based on that, we seek to improve the current mobility situation at our university by encouraging students and employees to choose a more environmentally-responsible arrival option in particular. Therefore, we raise the following research question: How can people be fostered to arrive in a more environmentally-friendly way at University Hildesheim?

In attempting to answer this question, we developed and evaluated a prototypical mobile app that aims at connecting several students and employees to collectively arrive at the university by means of carpooling. Based on a triangulation of literature on nudging and mobility, the analysis of an available university-wide survey [4], and interviews with students and staff from the university, we identified different problems and objectives in terms of how and why people decide on a certain mobility option. By using mechanisms of nudging these objectives were translated into different solution concepts from which the most promising approach has been selected and implemented through a prototype. For evaluation, students and employees were interviewed across several rounds to give detailed feedback on the prototypical app.

\section{Research Background: Mobility and Nudging}

The term 'mobility' refers to the means of transport, in this paper especially everyday transport as we focus on a specific case in which students and employees should select arrival options more responsibly. Many people rely on mobility, but it comes with financial as well as natural and societal costs such as huge amounts of greenhouse emissions caused by transportation, especially car traffic (e.g., see statistics in [2, 3]). Because of that, there is a need for more sustainable mobility. Whereas sustainability often distinguishes between ecological, economic, and social dimensions, this paper mostly focuses on ecological concerns, which are often called 'green'.

In attempting to face this challenge, research and practice have started to blend both streams of mobility and nudging. Generally, the verb nudge can be described as pushing somebody in a direction. In this mean, nudging does not try to intervene in the people's opinion but rather discretely influences them [9]. Referring to this study's context, 
nudging was used in other studies to influence mobility behavior such as in the online flight booking process [14]. Because many decision situations such as the flight booking process happen nowadays in digital environments, digital nudges can have a larger impact, even in real-world behavior [12]. Moreover, the high volume of information available in digital environments, but also the declining attention spans, makes rational choices harder [15]. Since previous research gives good reasons that nudging effectively motivates users to make more sustainable choices in terms of mobility, this paper especially relies on digital nudges. To operationalize nudging and to make it applicable in prototypes, there are several mechanisms that can be implemented. Table 1 gives more information about the different nudging mechanisms and how they can be used in a digital environment (based on [12, 13, 16-22]).

Table 1. Selected nudge mechanisms and exemplary use case

\begin{tabular}{|c|c|c|}
\hline Nudge mechanism & Description & Example of digital nudge \\
\hline Default settings & $\begin{array}{l}\text { Predefined and suggested } \\
\text { options that accelerate the } \\
\text { decision process }\end{array}$ & $\begin{array}{l}\text { The (online) cookie- } \\
\text { selection of a site is set to } \\
\text { "necessary" or "accept all" }\end{array}$ \\
\hline Expecting errors & $\begin{array}{l}\text { Expects errors from people } \\
\text { and being as forgiving as } \\
\text { possible when they do }\end{array}$ & $\begin{array}{l}\text { When typing, the software } \\
\text { automatically correct minor } \\
\text { mistakes }\end{array}$ \\
\hline Feedback & $\begin{array}{l}\text { The user is shown his/her } \\
\text { behavior and the influencing } \\
\text { factors that come with it }\end{array}$ & $\begin{array}{l}\text { Garmin Connect: Showing } \\
\text { the user data about their } \\
\text { latest workout }\end{array}$ \\
\hline Information & $\begin{array}{l}\text { Framing the information about } \\
\text { the decision to be made }\end{array}$ & $\begin{array}{l}\text { Instagram: Notifying when } \\
\text { a live stream of someone } \\
\text { they follow is started }\end{array}$ \\
\hline Incentive & $\begin{array}{l}\text { Encouraging the user by } \\
\text { giving them salient incentives }\end{array}$ & $\begin{array}{l}\text { TK Fit: Giving the user } \\
\text { badges and points that they } \\
\text { can redeem }\end{array}$ \\
\hline Social norms & $\begin{array}{l}\text { Represents the behavior or } \\
\text { decision of somebody else, } \\
\text { acting as a 'role model' }\end{array}$ & $\begin{array}{l}\text { WhatsApp: Showing the } \\
\text { user's online status and if } \\
\text { they read a message }\end{array}$ \\
\hline $\begin{array}{l}\text { Structure complex } \\
\text { choices }\end{array}$ & $\begin{array}{l}\text { Simplifying or reducing } \\
\text { alternatives in each decision } \\
\text { situation }\end{array}$ & $\begin{array}{l}\text { Immowelt: Implemented } \\
\text { filters so that just relevant } \\
\text { offers will be shown }\end{array}$ \\
\hline $\begin{array}{l}\text { Understanding } \\
\text { mapping (from } \\
\text { choice to welfare) }\end{array}$ & $\begin{array}{l}\text { Giving a clear choice } \\
\text { architecture with an overview } \\
\text { of the different characteristics } \\
\text { of a decision }\end{array}$ & $\begin{array}{l}\text { Google Maps: Showing the } \\
\text { duration that different } \\
\text { means of transportation } \\
\text { need }\end{array}$ \\
\hline
\end{tabular}




\section{$3 \quad$ Research Design}

The research design of this paper draws on two procedure models, namely the Design Science Research Methodology (DSRM) with a problem-centered initiation as proposed by Peffers et al. [23] and the Digital Nudge Design Method (DNDM) by Mirsch et al. [24] that complements the DSRM through specific activities for designing digital nudges (Figure 1). Even though we are aware of the availability of other methods for designing nudges that generally have some overlaps and similarities such as designing and testing the nudge (e.g., [25, 26]), we selected the DNDM because it details each of the abstract phases through sub-steps and is evaluated in terms of (practical) interviews that emphasize the applicability. Furthermore, we believe that the DNDM can be easily arranged with the DSRM.

The first phase, identify problem $\&$ motivate, started with a triangulation of a literature review, the analysis of an available mobility survey [4], and six interviews with the target group (i.e., students and employees of the university). First, the literature review was executed in three different databases: AISeL, Google Scholar, and Web of Science. Furthermore, articles from the journals Transportation Part $D$ and Part $F$ were included because we assume that these are helpful for the field of sustainable transportation. In total, 21 articles were examined. With the literature review, several requirements (REQ) could be derived, supporting an effective nudge development. Second, the results from the mobility survey gave more details about the case, the target group as well as the mobility behavior. Third, for structuring the interviews, the model from [27] was used. Six people were interviewed, taking into consideration that there had to be a range of different characters to explore different arrival situations and to possibly identify multiple approaches/situations that can be nudged.

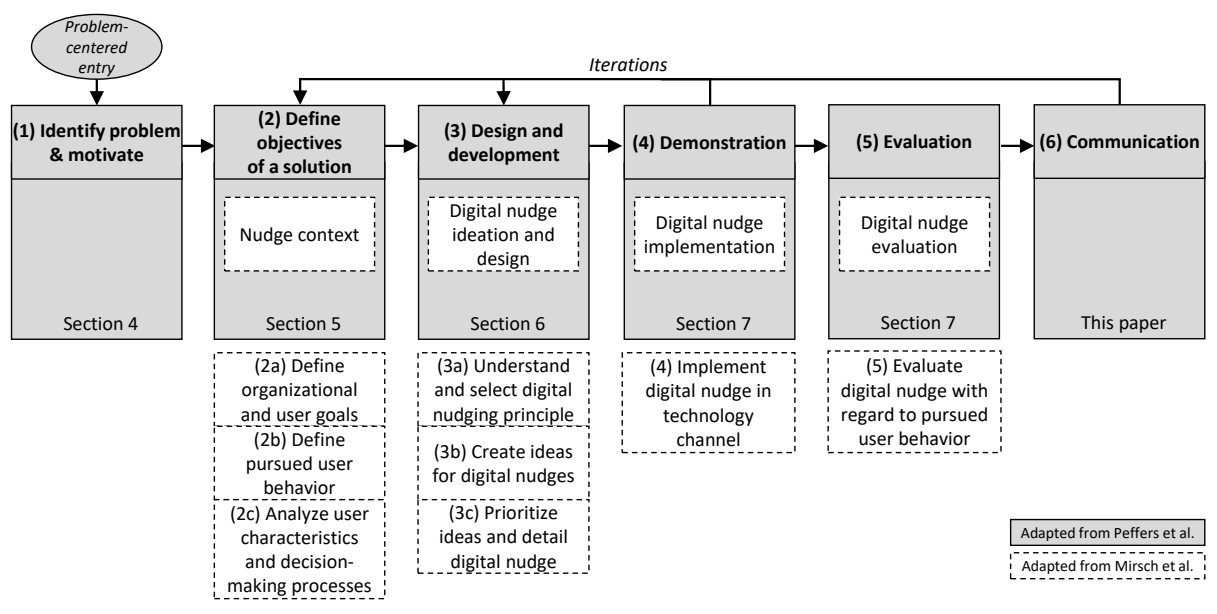

Figure 1. Overall research process (adapted from Peffers et al. and Mirsch et al.)

In the second phase, the objectives of the solution were defined based on the results of the triangulation, the obtained REQs in particular. Therefore, organizational and user 
goals were specified. This was done by analyzing the fundamental needs and primary goals of the interviewees. Besides, several user characteristics, and decision-making processes in terms of individual mobility options could be disclosed.

In the third phase, design and development, different nudging approaches were created within a brainstorming session. Reviewing the examples from the literature, the results from the mobility survey, and analyzing the interviews with the target group, the, in our opinion, most promising approach was selected for further prototype development, namely a mobile app for university-wide carpooling. Different options to address the target group with the approach of carpooling were created (i.e., different combinations of nudge mechanisms and designs), and prototypes were built.

For demonstration and evaluation, the prototype including its implemented nudges was used to illustrate potential usage scenarios as well as tested in three major evaluation activities: First, the participants were shown the prototype (i.e., mobile app) and should provide critical feedback; Second, after incorporating that feedback, the participants should provide positive feedback to the overall functions and the revised features; Third, the participants tested and rated the prototype's usability.

\section{Problem Formulation: The Case of the University Hildesheim}

The mobility survey done by the Green Office Hildesheim [4] indicates that $38,9 \%$ of the students and employees are unsatisfied and $15,7 \%$ very unsatisfied with the mobility situation regarding the arrival at University Hildesheim. They found out that especially the duration, costs, the distance between residence and university, access to supporting offers or platforms, as well as the ownership of, for example, a car or bike, can influence the mobility choice. Even though Hildesheim is a rather small city with about 100.000 residents, general-purpose (e.g., apps such as Google Maps) and cityspecific (i.e., offers that especially focus just on this city) in the form of analog and digital offers to arrive at the university are available, for example:

- Google Maps ${ }^{1}$ gives an overview of routes by foot, bike, and car.

- Citizens can arrive by bike, and in case of any damage or questions can participate in free workshops by $\mathrm{Fazz}^{2}$. Bulky items can be transported with so-called cargo bikes (Hilde Lastenrad ${ }^{3}$ ) that are useable free of charge.

- DB Navigator ${ }^{4}$ shows connections that are available by train or bus.

- Electric cars can be used, which are provided by the local electricity provider $E V I^{5}-$ recently introduced a prototype for electronic car-sharing.

- Various e-scooter can be rented across the city via a mobile app (TIER $\left.{ }^{6}\right)$

1 Google Maps: https://www.google.de/maps (Accessed:12.09.2020).

2 Fazze: https://fazze.asta-hildesheim.de/ (Accessed:12.09.2020).

3 Hilde Lastenrad: https://hilde-lastenrad.de/ (Accessed:12.09.2020).

4 DB: https://www.bahn.de/p/view/service/mobile/db-navigator.shtml (Accessed: 12.09.2020).

5 EVI: https://www.evi-hildesheim.de/ (Accessed: 12.09.2020).

6 TIER: https://www.tier.app/de/ (Accessed: 20.09.2020). 
Generally, students can use public transportation free of charge because of their student tickets. The employees do not have such an opportunity when it comes to public transport. Still, they can take advantage of the job ticket by the state of Lower Saxony to reduce the overall costs. Nevertheless, plenty of the students and employees from the university still rely on cars which reinforced the mentioned challenges.

\section{$5 \quad$ Specification of Solution Objectives}

In this section, we derive requirements (REQ) based on the literature on nudging and mobility that acts as the basis for our artifact. Afterward, we refined this set through interviews disclosing reasons why, for instance, students and employees rely on cars.

\subsection{Requirements and Objectives Based on Existing Literature}

As explained in the Research Design, three academic databases and additional journals for transportation were used to collect important aspects and findings from recent research. Our sample of 21 articles offered more information about how to create a nudge in the context of (sustainable) mobility. Not all these articles focused directly on nudging, but on related and adjacent topics such as decision-making [28], persuasive design [29], or gamification [30]. Also, different niches were explored, from smart charging [28], public transport systems [31, 32], sustainable travel [33], to general proenvironmental behavior [34]. During the analysis, we especially focus on tools that were used: Some of the explorative articles decided to work with apps, notifications, or feedback systems. Others chose to use offline possibilities like more space for pedestrians, cyclists, and busses [35] or test-tickets for trying public transportation services and convince the users of their advantages [36]. After examining the relevant articles, it was possible to develop REQs about how a nudge in terms of fostering mobility should look like. In the following, these REQs are presented in more detail.

The approach of tracking the user's activities and giving them feedback or more information about their behavior is used in more than half of the articles examined [28, 31, 37]. Ortmann et al. [38] summarized different behavioral intervention strategies towards a more efficient transportation system where the evidence for information/education is generally estimated as high. In the case of shifting travel to off-peak periods, it is rated with medium confidence. Bardal et al. [39] explored the "barriers for designing and implementing policies for the transition to more environmentally sustainable urban mobility" (p. 1). The authors identified that amongst other things, the lack of knowledge, evaluation, communication, or tools could be a barrier for the transitions to greener mobility. To face this, it is possible to make use of specific nudge mechanisms that draw on the lack of information, as presented in Section 2 (e.g., information, structure complex choices). Therefore, the following REQ is specified as follows: REQ1-The more information is available for the user about available alternatives, more sustainable ways to arrive at their destination, the more users would make more sustainable decisions in that matter. 
In the article 'goal framing in smart charging' [28], which also adopted the concept of Mirsch et al. [13] to nudge more flexible charging, the researchers allowed the user to set their own goals in terms of environmental, social, and financial aspects. The authors explained that goal-framing for reducing pollution regarding health led to 8$10 \%$ more energy conservation and, therefore, better decision-making. In general, six of the articles took fundamental needs or primary goals of the user into consideration while developing the nudge (e.g., [29, 40, 41]). Sandau et al. [31] built an architecture of a demand platform that includes the special demands and local road attributes so that the proposed trip would fit the users' needs and goals. Overall, it can be said that addressing fundamental needs or primary goals of the user could support a nudge. Therefore, the next REQ is specified as follows: REQ2-The more a nudge would address the fundamental mobility needs/primary mobility goals of a user, the more useful this nudge would be.

Andersen et al. [32] investigated smart nudging, including sensing, analyzing, and informing and nudging. They listed discouraging and encouraging factors for different transportation types to sense where the users could be hindered from using a specific means of transportation. To analyze the user, they listed main user profile dimensions, such as personal data or goals, and user-related information that could be useful for the nudging, like calendar events or current locations. They claimed that it is crucial to be aware of the user's current situation, their former ones, the plans like calendar events, but also bus and train schedules. Additional predictions about the weather, pollution levels, and schedule deviations were considered significant. With this personalized information, the nudge could have been more effective or, like the authors said: "smarter". Wallann [42] also emphasized that the current, past, and future weather "affect the travel decisions of people living in an area" (p. 14). Furthermore, the road conditions, traffic, parking situation, and health conditions are considered as important information, so that a nudge could also advise about outdoor clothing for specific means of transportation. Accordingly, the next REQ is specified as follows: REQ3-The more a nudge is personalized to the user, the more useful this nudge would be.

\subsection{Requirements and Objectives Based on Interviews}

Based on the initial list of requirements gathered from the literature, we sought to complement this through specific insights, needs, and challenges when choosing a means of transport from real students and employees of the university. These additional insights were intended to increase or decrease the importance of a single requirement in the context of our specific problem situation. To obtain this and understand how potential users make decisions in terms of mobility, six students and employees were interviewed. Each of the interviews was separated into five main blocks: First, general information about the arrival process including morning routines. Second, options that are available to arrive at the university as well as influencing factors and fundamental needs that are essential for choosing a means of transportation (e.g., Do you always use the same means of transportation? Why do you not choose other options?). Third, the general opinion about more environmental options, the awareness of all the possibilities to arrive at the university, and possible reasons to choose an ecological option (e.g., 
What do you think is the mist environmental option?). Fourth, validation of initial requirements from the literature (e.g., Would a financial incentive convince you to choose another option?), Fifth, personal information including courses details.

In a nutshell, half of the interviewees tried to make more environmental decisions on purpose (see $2,4,5$ ) like by avoiding domestic flights. One of them also stated that the factor to behave more sustainable may be a great thing to do, but for most, it is just one factor included in a bigger decision process. The other half of the interviewees choose environmental options without specific purposes (see 1, 3, 6). Next, we summarize the main observations and insights gained from the interviews.

Personal factors and needs. Table 2 summarizes the influencing factors and fundamental needs of the different interviewees when choosing a means of transport. It indicates that every person has different influencing factors and fundamental needs because every arrival situation is unique. The most common needs were cleanness, free space, low volume, and transportation from A to B. Taking a look at the influencing factors, costs, time to work or read, the daily schedule of the person, and the general environmental impact, were most often mentioned. Therefore, a nudge could include an aspect of personalization - supporting the initial REQ3.

Table 2. Summary of influencing factors for mobility choices and needs

\begin{tabular}{|c|c|c|c|}
\hline ID & Role & Influencing factors & Fundamental needs \\
\hline 1 & Student & $\begin{array}{l}\text { Comfort, costs, available time } \\
\text { to work/read during transport }\end{array}$ & $\begin{array}{l}\text { Cleanness, free space, low } \\
\text { background noises }\end{array}$ \\
\hline 2 & Student & $\begin{array}{l}\text { Costs, daily schedule, } \\
\text { environmental impact, } \\
\text { weather }\end{array}$ & $\begin{array}{l}\text { Customer experience, free } \\
\text { space, predictability, } \\
\text { regularity, reliability, security }\end{array}$ \\
\hline 3 & Student & Convenience, free space & Cleanness, punctuality \\
\hline 4 & Employee & $\begin{array}{l}\text { Daily schedule, exercise, } \\
\text { flexibility, health problems, } \\
\text { weather }\end{array}$ & $\begin{array}{l}\text { Free space, low background } \\
\text { noise, transport from A to B }\end{array}$ \\
\hline 5 & Employee & $\begin{array}{l}\text { Environmental impact, speed, } \\
\text { available time to work/read } \\
\text { during transport }\end{array}$ & $\begin{array}{l}\text { Comfort, environmental } \\
\text { impact, free space, time } \\
\text { maximum }\end{array}$ \\
\hline 6 & Employee & $\begin{array}{l}\text { Cleanness, costs, daily } \\
\text { schedule, available time to } \\
\text { work/read during transport, } \\
\text { transport luggage or } \operatorname{dog}(\mathrm{s})\end{array}$ & $\begin{array}{l}\text { Comfort, regularity, } \\
\text { transport from A to B }\end{array}$ \\
\hline
\end{tabular}

\subsection{Summary of Requirements and Objectives}

Table 3 synthesizes both the requirements derived from the literature and the interviews with students and employees. REQ1-3 have not been revised and REQ4-8 have been added during the interviews. 
Table 3. Requirements for the artifact to be developed (i.e., university carpooling)

\begin{tabular}{|c|c|}
\hline ID & Formulation of the requirement (REQ) \\
\hline REQ1 & $\begin{array}{l}\text { Information about the environmental impact of a means of transport } \\
\text { affects the user's behavior in terms of their mobility choices. }\end{array}$ \\
\hline REQ2 & $\begin{array}{l}\text { The more a nudge would address the user's mobility needs and primary } \\
\text { mobility goals, the more useful this nudge would be. }\end{array}$ \\
\hline REQ3 & $\begin{array}{l}\text { The more a nudge is personalized to the students or employees of the } \\
\text { University Hildesheim, the more useful this nudge would be. }\end{array}$ \\
\hline REQ4 & $\begin{array}{l}\text { More information about the means of transportation regarding } \\
\text { trustworthiness affects the behavior of the students and employees of the } \\
\text { University Hildesheim regarding their mobility choices. }\end{array}$ \\
\hline REQ5 & $\begin{array}{l}\text { More information about the means of transportation regarding reliability } \\
\text { affects the behavior of the students and employees of the University } \\
\text { Hildesheim regarding their mobility choices. }\end{array}$ \\
\hline REQ6 & $\begin{array}{l}\text { The possibility to connect with colleagues, fellow students, or professors } \\
\text { while arriving from the University Hildesheim affects the behavior of the } \\
\text { students and employees regarding their mobility choices. }\end{array}$ \\
\hline REQ7 & $\begin{array}{l}\text { Flexibility or keeping up with the daily schedules of a means of } \\
\text { transportation affects the behavior of the students and employees of the } \\
\text { University Hildesheim regarding their mobility choices. }\end{array}$ \\
\hline REQ8 & $\begin{array}{l}\text { The opportunity of working or reading while traveling affects the } \\
\text { behavior of the students and employees of the University Hildesheim } \\
\text { regarding their mobility choices. }\end{array}$ \\
\hline
\end{tabular}

\section{Design and Development}

After examining the REQs, different approaches to nudge the mobility options at University Hildesheim were created during creative brainstorming sessions. The most promising approach, discussed within the author team, was to simplify the building of carpools so that students and employees do not need to drive a car on their own when they, for instance, need to transport larger objects or need to be flexible in time. Carpooling has the potential to reduce the environmental impact, the costs when it comes to arriving at University Hildesheim, and the parking situation (see problem description) as well as allows for making new acquaintances. Moreover, even though there is a great environmental potential of carpooling as a mobility service, there is only limited research in information systems focusing on that topic [7]. As argued before, some people need to arrive by car and with our solution (i.e., carpools), we seek to still allow using cars in those cases where it is important (e.g., transport of bulky objects) but also to provide an approach that might have a lower impact on the environment. Referring to University Hildesheim, a user-organized system for carpool building would be suitable because there is already a huge amount of people arriving by car (as indicated by the mobility survey). 
Table 4. Implemented features and applied nudging mechanisms

\begin{tabular}{|c|c|c|}
\hline $\begin{array}{l}\text { Feature } \\
\text { category }\end{array}$ & Description of features $(F)$ & $\begin{array}{l}\text { Nudging } \\
\text { mechanism }\end{array}$ \\
\hline $\begin{array}{l}\text { Searching and } \\
\text { filtering }\end{array}$ & $\begin{array}{l}\text { Use filter }(F 1) \text { : Since people rely on cars } \\
\text { because of specific reasons, different filter } \\
\text { options such as taking children or the } \\
\text { possibility to work during the drive are } \\
\text { implemented to fit a carpool. }\end{array}$ & $\begin{array}{l}\text { Structure } \\
\text { complex } \\
\text { choices }\end{array}$ \\
\hline Rating & $\begin{array}{l}\text { - Create rating }(F 2) \text { : All users can rate each } \\
\text { other after the carpool regardless of being a } \\
\text { provider or consumer. }\end{array}$ & Feedback \\
\hline & $\begin{array}{l}\text { View ratings (F3): To overcome the barrier } \\
\text { of trust, users can see the rating of other } \\
\text { users to assess if they are trustworthy. }\end{array}$ & Social norms \\
\hline \multirow[t]{2}{*}{$\begin{array}{l}\text { Motivating } \\
\text { through } \\
\text { gamification } \\
\text { elements }\end{array}$} & $\begin{array}{l}\text { Perform quests }(F 4) \text { : When the user } \\
\text { accesses the application for the first time, } \\
\text { quests will be available that are easy to } \\
\text { complete, for example, booking or } \\
\text { providing their first carpool. }\end{array}$ & Incentive \\
\hline & $\begin{array}{l}\text { Earn achievements }(F 5) \text { : Users can receive } \\
\text { profile badges to visualize achievements. } \\
\text { - Compare rankings }(F 6) \text { : Through } \\
\text { leaderboards, users can compare their } \\
\text { achievements. } \\
\text { Give incentives (F7): The app indicates } \\
\text { what needs to be done to improve rankings. }\end{array}$ & $\begin{array}{l}\text { Feedback, } \\
\text { incentive } \\
\text { Feedback, } \\
\text { social norms }\end{array}$ \\
\hline
\end{tabular}

Being aware that the implementation of a carpooling mobile app could have different focuses such as on building trust between users or on punctuality through tracking cars, this study blends nudging mechanisms with elements proposed by gamification [43] in order to motivate users to participate in carpooling. In Table 4, we describe the main features implemented through our mobile app according to three categories, namely (1) searching and filtering, (2) rating, and (3) motivating through gamification elements.

Figure 2 presents exemplary screens of the prototype, i.e. the mobile app. The language in the prototype is German because it was tested at a German University. 


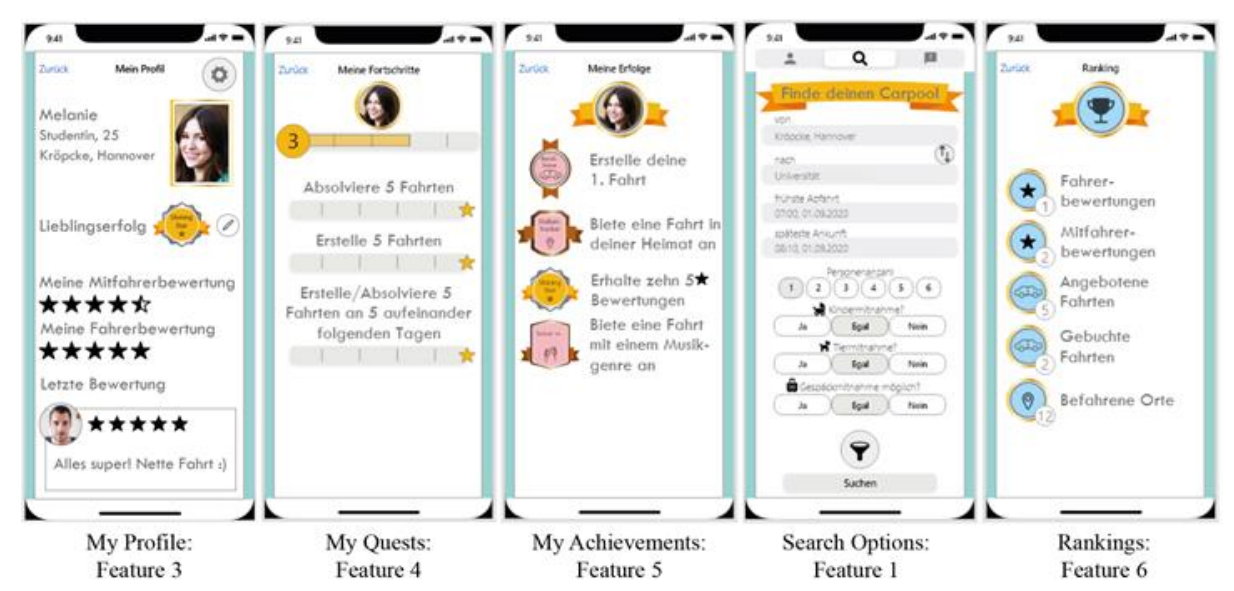

Figure 2. Prototype screen examples

\section{$7 \quad$ Demonstration and Evaluation}

For evaluation, three people were selected to give feedback to the prototype in three rounds. They all already participated in the previous interviews and therefore have a basic understanding of the facts discussed during the last sections. After each round, the prototype was adjusted according to the feedback given. In the first round, the participants gave critical feedback. Misunderstandings made in the previous interviews about the needs of the interviewed persons were discovered, such as specific search options. In the second round, all participants gave positive feedback highlighting the positive aspects of the prototype. The participants could test the usability with a clickable prototype in the third round. After that, they were asked to rate the prototype by usability-attributes. In the following, (1) feedback, lessons learned, and observations made across all evaluation rounds are provided (2) and the prototype is discussed in terms of how it fulfills the derived REQs.

Features for searching and filtering (1). To address the fundamental needs, the users could have the opportunity to differentiate between carpool offers by selecting given attributes as mentioned in the previous section. Through that, the user would have more structured information of a carpool and the possibility to evaluate if it fits their needs. The prototype sets the university as a standard destination or starting point. Search options for travel needs, like the possibility to work or read while traveling, could lead to more frequent use of the carpools provided (REQ3 and REQ8). To simplify the selection of different options, the main options that could change from day to day have to be selected every time, but more general options can be selected over a separate filter that is saved. With these options, the nudging mechanism of structuring complex choices is addressed, and the user will find a suitable carpool faster. Moreover, both users and providers do not have match details. Therefore, the prototypes implement feature for addressing the user's needs and the possibility to search for a carpool that is suitable for the unique personal situation (REQ2 and REQ3). Because a 
user can select to work or read during the carpool, REQ8 could be addressed. The users could also specify their latest departure and arrival time, which provides a sense of reliability (REQ5). Moreover, through building the carpools a connection to other students and employees is provided (REQ6). In the evaluation, all participants stated that this feature is necessary for a final version and implementation. The option to filter specific search settings on another site was added after it has been noted that is it laborious to select all the different search options every time. Also, search options were added and changed, for example, the possibility to select if the carpool was children friendly and gender selection was added.

Features for rating (2). Trust is a relevant factor when it comes to carpool building. As already mentioned in the interviews, when no trust or general knowledge of the person is available, driving, or taking them in their carpool becomes insecure. One possibility to overcome the barrier of trust is to let the users rate each other. An example of this is the application Google Play ${ }^{7}$, where the users can see the overall rating of an application, the comments of other users to explain their rating, but also the editor's recommendations about what they appreciate in the app. Another example is the application Kleiderkreisel ${ }^{8}$, where the users can rate each other after a transaction. In the example of University Hildesheim, a rating of other users, respectively, carpool providers, could increase the trust and, therefore, the use of the application in general (REQ3 and REQ4). We hope to achieve a sense of trust for the users and to provide information about the reliability of the users (REQ5). Participants of the evaluation, particularly for the positive feedback, rated this as an essential feature for the providing of feedback for their behavior.

Features for motivating through gamification elements (3). In broad terms, gamification employs game-mechanisms in a non-game-context to influence the user's behavior positively $[44,45]$. Referring to this study, this might be helpful as we seek to motivate carpool building in the sense of playing a game, for example, to get awards when providing the most carpools within a day - also known from other applications (e.g., Pokémon $\mathrm{Go}^{9}$ or [46]). Adapting this to the example of University Hildesheim, students and employees could also get rewards when, for example, providing or booking a specific number of carpools. In combination with a rating mechanism to support the trust between the users (REQ4), they could even get rewards when reaching a high number of five-star ratings. In the prototype built, typical gamification elements in the form of quests (i.e., tasks the user must fulfill to get rewards), achievements (i.e., rewards that can be collected such as in the form of points or badges), and ranking/leaderboards (i.e., an overview of all users and their progress in terms of achievements) were used (e.g., [45, 47-49]). By using the leaderboard element, for example, the app offers a comparison between the users, so that Social norms as a nudging mechanism can be also fostered. This also addresses REQ6 because of the social aspect to connect with other users and compare rankings. Besides, all

7 Google Play Store: https://play.google.com/store (Accessed: 20.09.2020).

8 Kleiderkreisel: https://www.kleiderkreisel.de/app (Accessed: 20.09.2020).

9 Pokémon Go: https://pokemongolive.com/de/ (Accessed: 20.09.2020). 
gamification elements provide a feedback mechanism for the user, which can support the regular use of the application.

Before the first evaluation was performed, the gamification elements were not visible on the starting screen when entering the application. The participants stated that it could be useful to see the users' progress immediately after entering the application. Therefore, the level-bar was added to the first site and the overview with the quests. By completing quests, the user can collect points that raise their level. Moreover, the overall theme of the gamification-element design was included in the whole prototype. One participant suggested adding little stars at the end of each quest-bar to make the possibility of an achievement more visible. Moreover, the possibility to show other users their favorite achievement was added. In summary, all participants agreed that the gamification elements gave an effective incentive to use the app more often.

Additional features and design decisions. Besides gaining insights regarding features that are already implemented, evaluation participants suggested additional features and comments in terms of the prototype design: First, the selection of nearby bus stops or subway stations as pick up locations to protect the user's privacy, which would also reduce the required information to pick up users, for example. Second, as a payment system, a non-commercial variant such as buying and receiving free kilometers for the carpool would be conceivable - this would also cover the costs of the carpool providers. Third, since all participants like the idea of gamification, they suggested implementing the gamification design throughout the entire applicationtherefore, gender-specific design of questions, for instance, need to be considered.

\section{Discussion and Conclusion}

\subsection{Summary and Implications}

Mobility is an essential prerequisite to support positive aspects such as meeting friends and family, engaging with other cultures, or getting to work. In contrast, mobility can have negative impacts on the natural environment, particularly in terms of greenhouse emissions $[2,3]$ that need to be taken into account. Therefore, novel approaches such as sharing vehicles need to be promoted. From a more specific view, this study's case of the University Hildesheim faces challenges in terms of restricted parking lots, emissions, and traffic jams in particular. Against this backdrop, the present study raised the research question of how people can be fostered to arrive in a more environmentally-friendly way at University Hildesheim. For answering this question, we combined approaches from design science and digital nudging to plan the activities for developing and evaluating a mobile app that makes use of nudge mechanisms.

In doing this, our contribution is threefold: First, we derived a set of eight requirements (REQ1-REQ8) from literature, a university-wide mobility survey, and interviews with students and employees. These requirements served as a foundation for the development of our artifact but also can be picked up in further studies that aim at designing nudges for mobility. Second, we developed and evaluated a prototypical mobile app for carpooling at our university. With this app, we hope to pool different 
students and employees to collectively arrive at the university and thereby help to reduce the number of required parking lots as well as the general traffic during the university's peak times. Moreover, since there is only limited IS research on carpooling in the context of sustainable mobility [7], we provide an artifact that complements current research streams in this field. Third, we contribute to the research stream of digital nudging $[12,13]$ by laying a focus on the achievement of more sustainable arrival procedures through carpooling - especially environmentally-friendly arrival. Our nudges complement the repertoire of available nudges for mobility such as [50] who developed a nudge in the form of a reminder card placed on the windshield that visually reminds carsharing users to inspect the car before starting with the trip, [14] who examined different nudges for reducing emissions during flight booking, or [51] who investigated how eco-labels can help to select more sustainable vehicles.

\subsection{Limitations and Future Directions}

Even though we could obtain some promising results, our study is not free of limitations, which open avenues for future research endeavors. First, since we evaluated the entire prototype, we could hardly provide information on (a) which nudges are most effective and (b) which nudges are leveraged by which gamification-elements. Further research may focus on separating these items and test them individually in experiments. Second, whereas we focus on the implementation of digital nudges, which is in line with the available literature (e.g., half of the articles prefer digital solutions), analog nudges might be helpful too. We believe that digital nudges are more suitable for this study's case because students and employees are used to rely on digital technology and make use of this in their daily life. The potential of digital nudges is further evident by research (e.g., $[12,13])$ who emphasized the increasing use of digital devices. Besides these effects, it might however be helpful to explore how analog nudges can be implemented to support the general use of the carpooling app. As an example, some interviewees discussed points such as providing an initial credit of free kilometers when students matriculate at the university. Accordingly, some default options can leverage the actual use and popularity of the app. Third, while related literature often provides approaches that focus on creating awareness for acting environmentally-friendly (e.g., $[16,34,37])$, we especially focus on nudging people for action. The prototype focuses on the users themselves and their needs. Nonetheless, the combination of awareness and action is already emphasized in previous research for which reason future steps could (a) investigate whether the prototype has already an effect on the user's awareness and (b) how the prototype might be complemented to address both. For instance, it could be helpful to provide information about the positive factors such as emissions of carpool building in terms of the environment. Fourth, the prototype does not include financial incentives because of the inconsistencies between the literature and the interviews. The next steps could deal with (a) investigating under which circumstances it makes sense to integrate financial features and (b) how this might look like.

Nonetheless, the preliminary evaluation gives promising indications that the carpooling app will be used by students and employees of the university, which ultimately may contribute to sustainable mobility. 


\section{References}

1. Grelier, F.: $\mathrm{CO}_{2}$ Emissions from Cars: The Facts. Transport \& Environment, European Federation for Transport and Environment AISB, Brussels, Belgium (2018)

2. Umweltbundesamt: Emission der von der UN-Klimarahmenkonvention abgedeckten Treibhausgase. Umweltbundesamt, Nationale Treibhausgas-Inventare, UBA (2020)

3. BMU (Bundesministerium für Umwelt, Naturschutz und nukleare Sicherheit): Klimaschutz in Zahlen: der Sektor Verkehr, www.bmu.de/publikationen (2019)

4. Green Office Hildesheim: Mobilitätsbefragung 2019/2020. Universität Hildesheim (2019)

5. Schoormann, T., Behrens, D., Knackstedt, R.: Carsharing Geschäftsmodelle - Entwicklung eines bausteinbasierten Modellierungsansatzes. In: Thomas, O., Nüttgens, M., Fellmann, M. (eds.) Smart Service Engineering: Konzepte und Anwendungsszenarien für die digitale Transformation. pp. 303-325. Springer Fachmedien, Wiesbaden (2017)

6. Degirmenci, K., Breitner, M.: Carsharing: A literature review and a perspective for information systems research. In: Multikonferenz Wirtschaftsinformatik. Paderborn, Germany (2014)

7. Brendel, A., Mandrella, M.: Information Systems in the Context of Sustainable Mobility Services: A Literature Review and Directions for Future Research. In: Americas Conference on Information Systems. San Diego, CA, USA (2016)

8. Lehner, M., Mont, O., Heiskanen, E.: Nudging - A promising tool for sustainable consumption behaviour? Journal of Cleaner Production. 134, 166-177 (2016)

9. Thaler, R.H., Sunstein, C.R.: Nudge: Improving decisions about health, wealth, and happiness. Penguin (2009)

10. Hildebrandt, B., Hanelt, A., Piccinini, E., Kolbe, L., Nierobisch, T.: The Value of IS in Business Model Innovation for Sustainable Mobility Services - The Case of Carsharing. In: Wirtschaftsinformatik. Osnabrück, Germany (2015)

11. Schoormann, T., Behrens, D., Kolek, E., Knackstedt, R.: Sustainability in Business Models-A Literature-Review-Based Design-Science-Oriented Research Agenda. In: European Conference on Information Systems. Istanbul, Turkey (2016)

12. Weinmann, M., Schneider, C., Brocke, J. v.: Digital Nudging. Bus Inf Syst Eng. 58, 433436 (2016)

13. Mirsch, T., Lehrer, C., Jung, R.: Digital Nudging: Altering User Behavior in Digital Environments. In: Wirtschaftsinformatik, pp. 634-648. St Gallen, Switzerland (2017)

14. Székely, N., Weinmann, M., Brocke, J. v.: Nudging People to Pay $\mathrm{CO}_{2}$ Offsets - The Effect of Anchors in Flight Booking Processes. In: European Conference on Information Systems. Istanbul, Turkey (2016)

15. Lembcke, T.-B., Engelbrecht, N., Brendel, A.B., Herrenkind, B., Kolbe, L.M.: Towards a Unified Understanding of Digital Nudging by Addressing its Analog Roots. In: Pacific Asian Conference on Information Systems. Xi' an, China (2019)

16. Byerly, H., Balmford, A., Ferraro, P.J., Wagner, C.H., Palchak, E., Polasky, S., Ricketts, T.H., Schwartz, A.J., Fisher, B.: Nudging pro-environmental behavior: evidence and opportunities. Frontiers in Ecology and the Environment. 16, 159-168 (2018)

17. Löfgren, A., Nordblom, K.: A theoretical framework explaining the mechanisms of nudging. Department of Economics, University of Gothenburg (2019)

18. Garmin Connect: Garmin Connect, https://connect.garmin.com/ (Accessed: 12.12.2020) 
19. Immowelt: Immobilienangebote als mobile Apps, https://aktion.immowelt.ag/de/app/?_ga $=2.128939212 .1794498132 .1599830182-630382709.1597767396$ (Accessed: 12.12.2020)

20. Instagram: Instagram, https://www.instagram.com/ (Accessed: 12.12.2020)

21. Google Maps: Google Maps, https://www.google.de/maps (Accessed: 12.12.2020)

22. Techniker Krankenkasse: Die TK-App, https://www.tk.de/techniker/leistungen-undmitgliedschaft/online-services-versicherte/die-tk-app-2027886 (Accessed: 12.12.2020)

23. Peffers, K., Tuunanen, T., Rothenberger, M.A., Chatterjee, S.: A Design Science Research Methodology for Information Systems Research. Journal of Management Information Systems. 24, 45-77 (2007)

24. Mirsch, T., Lehrer, C., Jung, R.: Making Digital Nudging Applicable: The Digital Nudge Design Method. In: International Conference on Information Systems. San Francisco, CA, USA (2018)

25. Schneider, C., Weinmann, M., vom Brocke, J.: Digital Nudging-Guiding Choices by Using Interface Design. Communications of the ACM. 61, 67-73 (2017)

26. Meske, C., Potthoff, T.: The DINU-Model - A Process Model for The Design of Nudges. In: European Conference on Information Systems, pp. 2587-2597. Guimarães, Portugal (2017)

27. Krell, C., Lamnek, S.: Leitfaden, https://www.beltz.de/fileadmin/beltz/downloads/Online materialienPVU/28269_Lamnek/(2)_Qualitatives_Interview/Beispielleitfaden.pdf (2016)

28. Huber, J., Jung, D., Schaule, E., Weinhardt, C.: Goal Framing in Smart Charging Increasing BEV Users' Charging Flexibility with Digital Nudges. In: European Conference on Information Systems. Stockholm-Uppsala, Sweden (2019)

29. Anagnostopoulou, E., Bothos, E., Magoutas, B., Mentzas, G., Stibe, A.: How to not be Annoying: Adjusting Persuasive Interventions Intensity when Nudging for Sustainable Travel Choices. In: Personalization in Persuasive Technology Workshop, Persuasive Technology, pp. 88-92. Waterloo, Canada (2018)

30. Lieberoth, A., Holm, N., Bredahl, T.: Selective psychological effects of nudging, gamification and rational information in converting commuters from cars to buses: A controlled field experiment. Transportation Research Part F. 55, 246-261 (2018)

31. Sandau, A., Gómez, J.M., Stamer, D., vom Berg, B.W., Halberstadt, J.: Model of mobility demands for future short distance public transport systems. In: CONF-IRM (2016)

32. Andersen, A., Karlsen, R., Yu, W.: Green Transportation Choices with IoT and Smart Nudging. In: Maheswaran, M. and Badidi, E. (eds.) Handbook of Smart Cities: Software Services and Cyber Infrastructure. pp. 331-354. Springer International Publishing, Cham (2018)

33. Andersson, H.: Designing Digital Nudges for Sustainable Travel Decisions, http://urn.kb.se/resolve?urn=urn:nbn:se:umu:diva-161076, (2019)

34. Henkel, C., Seidler, A.-R., Kranz, J., Fiedler, M.: How to nudge pro-environmental behaviour: An experimental study. In: European Conference on Information Systems. Stockholm-Uppsala, Sweden (2019)

35. Freudendal-Pedersen, M.: Sustainable urban futures from transportation and planning to networked urban mobilities. Transportation Research Part D: Transport and Environment. 82,102310 (2020)

36. Thorun, C., Diels, J., Vetter, M., Reisch, L., Bernauer, M., Micklitz, H.-W., Purnhagen, K., Rosenow, J., Forster, D., Ricardo-AEA, O.U.: Nudge-Ansätze beim nachhaltigen Konsum: 
Ermittlung und Entwicklung von Maßnahmen zum „Anstoßen “nachhaltiger Konsummuster (2016)

37. Baird, T.D.: Towards nudging active travel: behavioral interventions using mobile technology. Master Thesis, University of Wisconsin, USA, https://open.library.ubc.ca/ cIRcle/collections/ubctheses/24/items/1.0166848, (2014)

38. Ortmann, A., Dixit, V.: Nudging towards a more efficient transportation system: A review of non-pricing (behavioural) interventions. Unpublished Manuscript (2017)

39. Bardal, K.G., Gjertsen, A., Reinar, M.B.: Sustainable mobility: Policy design and implementation in three Norwegian cities. Transportation Research Part D: Transport and Environment. 82, 102330 (2020)

40. Pihlajamaa, O., Heino, I., Kuisma, S.: Nudging towards sustainable mobility behaviour in nature destinations: Parkkihaukka mobile information service. In: ITS European Congress. Brainport, Netherlands (2019)

41. Riggs, W.: Painting the fence: Social norms as economic incentives to non-automotive travel behavior. Travel Behaviour and Society. 7, 26-33 (2017)

42. Wallann, H.: RoadAhead - Removing Uncertainty in Travel. Creating a Data Warehouse for Green Transportation Nudging, Master thesis, The Arctic University of Norway, Norway, https://munin.uit.no/handle/10037/15735 (2019)

43. Blohm, I., Leimeister, J.M.: Gamification: Gestaltung IT-basierter Zusatzdienstleistungen zur Motivationsunterstützung und Verhaltensänderung. Wirtschaftsinf. 55, 275-278 (2013)

44. Deterding, S., Khaled, R., Nacke, L.E., Dixon, D.: Gamification: Toward a definition. In: CHI 2011 Gamification Workshop. Vancouver BC, Canada (2011)

45. Schacht, S., Morana, S., Mädche, A.: The Project World - Gamification in Project Knowledge Management. In: European Conference on Information Systems. Tel Aviv, Israel (2014)

46. Vinichenko, M.V., Melnichuk, A.V., Kirillov, A.V., Makushkin, S.A., Melnichuk, Y.A.: Modern Views on the Gamification of Business. The Journal of Internet Banking and Commerce (1970)

47. Sailer, M., Hense, J., Mandl, J., Klevers, M.: Psychological perspectives on motivation through gamification. Interaction Design and Architecture Journal. 28-37 (2014)

48. Wiegand, T., Stieglitz, S.: Serious Fun-Effects of Gamification on Knowledge Exchange in Enterprises. In: GI-Jahrestagung, pp. 321-332 (2014)

49. Swacha, J.: Gamification in knowledge management: motivating for knowledge sharing. Polish Journal of Management Studies. Vol. 12, No. 2, (2015)

50. Namazu, M., Zhao, J., Dowlatabadi, H.: Nudging for responsible carsharing: using behavioral economics to change transportation behavior. Transportation. 45, 105-119 (2018)

51. Folkvord, F., Veltri, G.A., Lupiáñez-Villanueva, F., Tornese, P., Codagnone, C., Gaskell, G.: The effects of ecolabels on environmentally-and health-friendly cars: an online survey and two experimental studies. The International Journal of Life Cycle Assessment (2019) 